\title{
AN ATTEMPT TO LOCATE THE TRANSVERSE AXIS OF TEMPOROMANDIBULAR JOINT BY ADAPTING A NEW METHOD
}

\author{
Sidharth Sankar Maharana ${ }^{1}$, Gopichand V. V. Patnaik², Purna Chandra Maharana ${ }^{3}$
}

1Ph.D Research Scholar, Department of Anatomy, MMIMSR, Mullana-Ambala, Haryana.

2 Professor, Department of Anatomy, MMIMSR, Mullana-Ambala, Haryana.

3Professor and HOD, Department of Anatomy, GVPIHC and MT, Visakhapatnam, Andhra Pradesh.

\section{ABSTRACT}

\section{BACKGROUND}

The present study is aimed to ascertain the position of transverse axis of temporomandibular joint in living subjects by devising a new method, which remains hypothetical till date with a hope that it can help the biomechanical engineers and Orthodontic surgeons to go for manufacturing suitable prosthesis for patients with fractured jaw.

\section{MATERIALS AND METHODS}

The present study was conducted at MMIMSR, Mullana-Ambala, Haryana on 1200 subjects (600 males and 600 females) belonging to three states (Haryana, Himachal Pradesh and Odisha) of India. The superimposition method adapted in which two triangles have been constructed (i.e. triangle of closed mouth and triangle of opened mouth) by selecting three bony landmarks (Na- Nasion, CyCondylion and Go- Gonion) and taking three measurements (Na-Cy, Na-Go and Cy-Go).

\section{RESULTS}

The study revealed that in average the transverse axis is positioned $11 \mathrm{~mm}$ above Midramus Point (MRP) in $94.08 \%$ of total population, at MRP in $0.92 \%$ and below MRP in 5\% cases. Similarity in the findings was seen between Haryanvi and Himachali population as well as between Himachali and Odisha males. It is above MRP in 95.58\%, at MRP in 0.67\% and below MRP in $3.75 \%$ of all males; above MRP in $92.58 \%$, at MRP in $1.17 \%$ and below MRP in $6.25 \%$ of females of three states.

\section{CONCLUSION}

Bilateral symmetry is maintained in the position of transverse axis with minimum difference in females of three states compared to males. Bilateral symmetry is well maintained in Himachali females.

\section{KEYWORDS}

Nasion (Na), Condylion (Cy), Gn (Gonion), Temporomandibular Joint (TMJ), Terminal Hinge Axis, Transverse Axis.

HOW TO CITE THIS ARTICLE: Maharana SS, Patnaik GVV, Maharana PC. An attempt to locate the transverse axis of temporomandibular joint by adapting a new method. J. Evolution Med. Dent. Sci. 2017;6(37):3014-3018, DOI: $10.14260 /$ Jemds/2017/650

\section{BACKGROUND}

The Temporomandibular Joint (TMJ) is an extraordinary peculiar type of bicondylar ginglymoarthrodial joint when its morphology, development and functions are concerned. The temporomandibular joint of both the sides cannot function entirely independently of each other; they also rarely function with identical concurrent movement. ${ }^{1}$ This joint is also a compound, complex and complicated synovial joint as the mandibular movements occur in a complex series of interrelated three dimensional rotational and translational activities, particularly during normal activities of closing and opening of mouth which are difficult to appreciate or visualise. $^{2}$

The rotational movements can occur in all three reference planes in the inferior compartment of the temporomandibular joint and translation occurs in the superior compartment.

Financial or Other, Competing Interest: None.

Submission 04-03-2017, Peer Review 25-04-2017,

Acceptance 01-05-2017, Published 08-05-2017.

Corresponding Author:

Sidharth Sankar Maharana,

Ph.D Research Scholar,

MMIMSR, Mullana-Ambala-133207,

Haryana, India.

E-mail: siddharth.maharana@gmail.com

DOI: $10.14260 /$ jemds $/ 2017 / 650$
The process of opening of mouth comprises of two stages. At the beginning (First stage) when the condyles are stabilised in their most superior or centric relation position (CR), the jaw is rotated around its terminal hinge axis that passes through the two poles of two condyles without translation and mouth opened up to the range of $20-25 \mathrm{~mm}$ for the purpose of talking and respiration. This is the first stage hinging movement, a component of posterior opening border movement of mandible around the terminal hinge axis in the sagittal plane. The second stage hinging movement of mandible occurs for further wide opening of mouth up to 40 $60 \mathrm{~mm}$ around the transverse axis of temporomandibular joint that runs through the ramus at some point below the condylion with the forward displacement of condyles (Translation) down to the articular eminence.

The exact position of the transverse axis of temporomandibular joint below the condyles is not yet ascertained till date, but likely to be present at the lower attachment of sphenomandibular ligament ${ }^{4}$ or mandibular foramina ${ }^{5}$ or base of lingula. ${ }^{6}$ The aim of the present study is to locate the transverse axis of temporomandibular joint by adapting a new superimposition method.

\section{MATERIALS AND METHODS}

The present study was conducted at three places Mullana (Haryana), Solan (Himachal Pradesh) and Berhampur (Odisha) on 1200 subjects (600 males and 600 females) of 18 
- 25 years' age group. Ethical clearance certificate was obtained from the Institutional Research Ethical Committee (Human).

The subjects were screened out by using appropriate inclusion and exclusion criteria for the study setup. All the subjects were apparently healthy with normal masticatory function as regards to opening and closing of mouth without any defects or disorder in function of their temporomandibular joints and free from any obvious physical deformity, mainly craniofacial deformity and trauma.

The anatomical landmarks- Nasion ( $\mathrm{Na}$ ), Condylon $(\mathrm{Cy})$ and Gonion (Go) were marked.

Three anthropometric measurements were taken by using the three bony landmarks with the mouth closed (intercuspation position) and wide open with the help of sliding caliper and the person sitting on the chair in relaxed state and head is in the anatomical position (Fig. 1a, b).

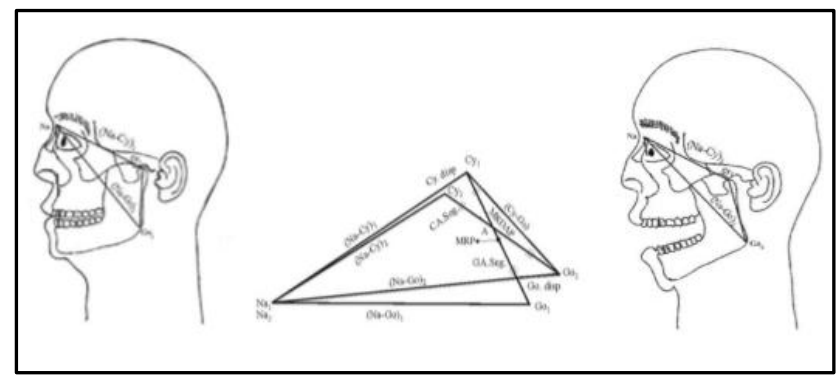

Fig.1a- $\Delta_{1}$, Fig.1c- $\Delta_{1}$ and $\Delta_{2}$ Superimposed Fig. $1 b-\Delta_{2}$

Figure 1- Showing three measurements and two triangles $(\Delta)$ mouth closed (Fig. 1a) and wide open state (Fig. 1b).

The three measurements taken with the mouth closed were- (Na-Cy) ${ }_{1},(\mathrm{Na}-\mathrm{Go})_{1}$ and (Cy-Go) (Fig. 1a).

Three measurements taken with the mouth wide open were- (Na-Cy)2, (Na-Go) 2 and (Cy-Go) (Fig. 1b).

The Midramus Point (MRP) was derived as half of the length of the ramus (Cy-Go) and it is the midway between condylion and gonion. Two triangles, first triangle $\left(\Delta_{1}\right)$ with the mouth closed and second triangle $\left(\Delta_{2}\right)$ with the mouth wide open were constructed with the help of these three measurements. The first triangle (Nasion, condylion, gonion triangle) 1 was preferably constructed on a sheet of white paper and the second one (Nasion, condylion, gonion triangle) 2 on a sheet of sketch paper. The second triangle on the sketch paper was made superimposed with that of the first triangle drawn on the white paper in such a way that the nasion points of the two triangles were kept in coinciding with each other and fixed with the tip of the left hand index finger, while the other edge of the sketch paper held by the right hand was made moving till the (Cy-Go) arms of two triangles were intersected with each other at some point. This process was continued till the point of intersection on the (Cy-Go) arm confirmed as axis point (Ax) when either the upper segments (CA) or lower segments (GA) of two triangles became almost equal with the help of a divider and a scale (Fig. 1a, b, c).

After the axis point was determined by this new method of superimposition, the following measurements were taken with the help of a divider and a scale to get the relative position of the transverse axis point on the ramus (Cy-Go arm).
The measurements were- upper segments of the ramus (CA segment), lower segment (GA segment), midramus point (MRP), the midramus deviation of axis point (MRDAP) as the difference between the MRP and CA or GA segment and the CA segment-GA segment index (CAGAI) was calculated as the percentage of the ratio between the CA and GA segments.

\section{Statistical Analysis}

All the parameters were subjected to statistical analysis by using Microsoft Excel- 2007 and presented as mean, range and pie diagrams for observation and conclusion.

\section{RESULTS}

The mean CAGAI (Upper and lower segment index in reference to the axis point) on total population is 50.09 , on right side 50.15 and on left side 50.03. In males the mean CAGAI is 47 on right and left side and in females 54.03 on both sides. It shows that in an average the transverse axis is situated in the midway between the midramus point and condylion, i.e. at the junction between the upper one-fourth and lower three-fourth of the ramus. As the mean CAGAI is less in males than in females, it reveals the position of the axis more towards the condylion in males and towards MRP in females. Bilateral symmetry is maintained in the position of the axis with negligible bilateral difference in the mean CAGAI.

The CAGAI range 8 - 39.99 is seen in $41.17 \%$ and 40 79.99 in 46.88 of total population. On the right side, the range is $8-39.99$ in $39.58 \%$ and $40-79.99$ is $48 \%$; on the left side 8 - 39.99 in $42.75 \%$ and 40 - 79.99 in $45.75 \%$ of study population. In males, the range is $8-39.99$ in $48.33 \%$ and 40 79.99 in $41.33 \%$ cases; in females the range is $8-39.99$ in $34 \%$ and $40-79.99$ in $52.42 \%$ cases. It is observed that in more number of cases $(48.33 \%)$ of males the CAGAI range is 8 - 39.99 and in (52.42\%) of females come under the range 40 - 79.99. Bilateral symmetry has been marked in males when these two specific ranges are considered, but bilateral variation is seen in females.

Midramus Deviation of Axis Point (MRDAP), i.e. the distance of the axis point in reference to the Midramus Point (MRP) in this study reveals the mean value of $11.08 \mathrm{~mm}$ on total population, $11.07 \mathrm{~mm}$ on right side and $11.09 \mathrm{~mm}$ on left side. In an average, the transverse axis is situated on the ramus $11 \mathrm{~mm}$ above the MRP and showing bilateral symmetry in the position of the axis.

In majority of the population (73.79\%), the MRDAP range is $5.5-20 \mathrm{~mm}$ and the MRDAP range is $-8-5 \mathrm{~mm}$ in $18.67 \%$ of cases and the axis situated nearer to the MRP (above or at or below MRP). The range is $20.5-30 \mathrm{~mm}$ in $7.55 \%$ cases and the axis is found close to the condylion. The MRDAP range is $5.5-20 \mathrm{~mm}$ in $71.67 \%$ on the right side and $75.92 \%$ on the left side. It is $-8-5 \mathrm{~mm}$ in $19.59 \%$ on the right side and $17.75 \%$ on the left side, $20.5-30 \mathrm{~mm}$ in $8.75 \%$ on the right side and $6.33 \%$ on the left side.

The position of the transverse axis in relation to Midramus Point (MRP) reveals that in total population of three states it is situated above MRP in $94.08 \%$, at MRP $0.92 \%$ and below MRP in 5\% cases; on the right side above MRP in $94.83 \%$, at MRP in $0.83 \%$ and below MRP in $4.33 \%$; 
and on the left side above MRP in 93.33\%, at MRP 1\% and below MRP $5.67 \%$ cases.

Total males of three states present their axis above MRP in $95.58 \%$, at MRP in $0.67 \%$ and below MRP in $3.75 \%$ cases while the females above MRP in $92.58 \%$, at MRP in $1.17 \%$ and below MRP in $6.25 \%$ cases. In males on the right side above MRP in $97.67 \%$, at MRP in $0 \%$ and below MRP in $2.33 \%$ while on the left side above MRP in $93.5 \%$, at MRP in $1.33 \%$ and below MRP in $5.17 \%$ cases. In females on the right side above MRP in 92\%, at MRP in $1.67 \%$ and below MRP in $6.33 \%$, while on the left side above MRP in $93.17 \%$, at MRP in $0.67 \%$ and below MRP in $6.17 \%$ cases.

The Haryanvi males present their axis on the right side above MRP in $98.5 \%$, no cases at MRP and below MRP in $1.5 \%$ cases, while on the left side above MRP in 95\%, at MRP in $1.5 \%$ and below MRP in $3.5 \%$ cases. In Haryanvi females on the right side, it is situated above MRP in $92.5 \%$, at MRP in $2 \%$ and below MRP in 5.5\%, while on the left side above MRP in $94 \%$, at MRP in $0.5 \%$ and below MRP in $5.5 \%$ cases (Figs. 2a, 2b, 2c and 2d).

The Himachali males on the right side present their axis above MRP in 97.5\%, at MRP in no cases, below MRP in 2.5\%, while on the left side above MRP in 93\%, at MRP in 1\% and below MRP in $6 \%$ cases. In females on the right side above MRP in $95.5 \%$, at MRP in $0.5 \%$ and below MRP in $4 \%$, while on the left side above MRP in $95.5 \%$, at MRP in no cases, below MRP in $4.5 \%$. Bilateral symmetry is maintained in position of the axis in Himachali females during closing and opening of mouth (Figs. 3a, 3b, 3c and 3d).

The Odisha males on the right side present their axis above MRP in 97\%, at MRP in no cases and below MRP in $97 \%$, at MRP in no cases and below MRP in 3\%; while on the left side above MRP in $92.5 \%$, at MRP in $1.5 \%$ and below MRP in $6 \%$ cases. In females on the right side above MRP in $88 \%$, at MRP in $2.5 \%$ and below MRP in $9.5 \%$; while on the left side above MRP in $90 \%$, at MRP in $1.5 \%$ and below MRP in $8.5 \%$ case. The Odisha females also maintain bilateral symmetry in the position of the axis to some extent with negligible difference during closing and opening of the mouth (Figures $4 \mathrm{a}, 4 \mathrm{~b}, 4 \mathrm{c}$ and $4 \mathrm{~d})$.

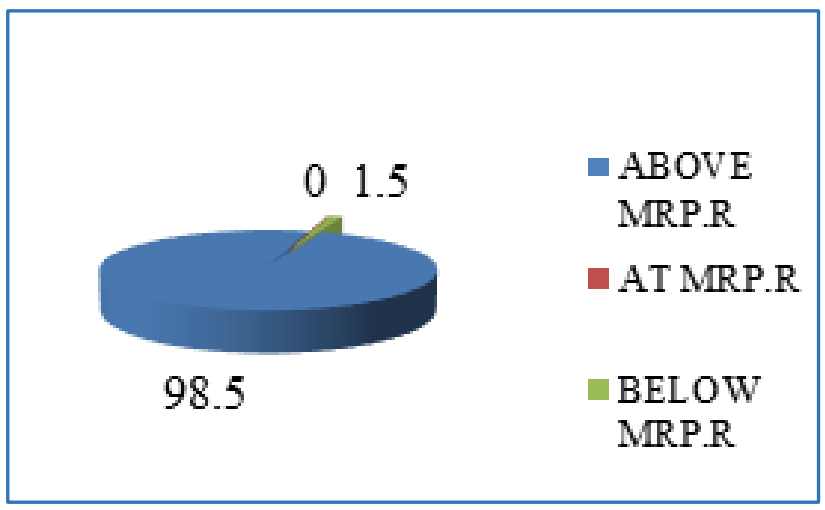

Fig. 2a- Position of Axis in Relation to MRP-HR (Male)-R

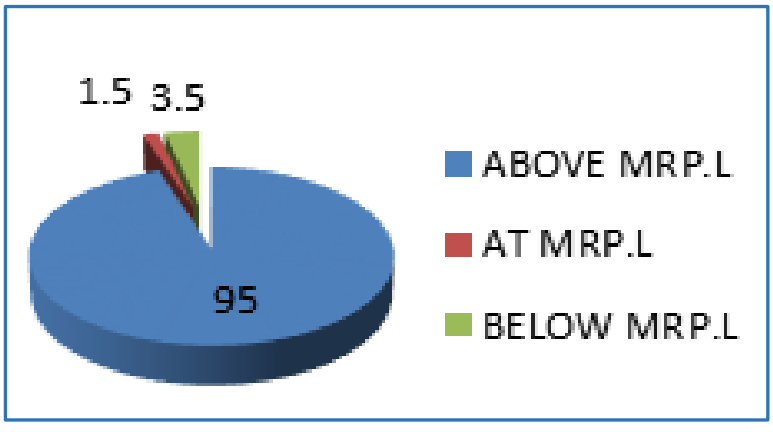

Fig. 2b-Position of Axis in Relation to MRP-HR (Male)-L

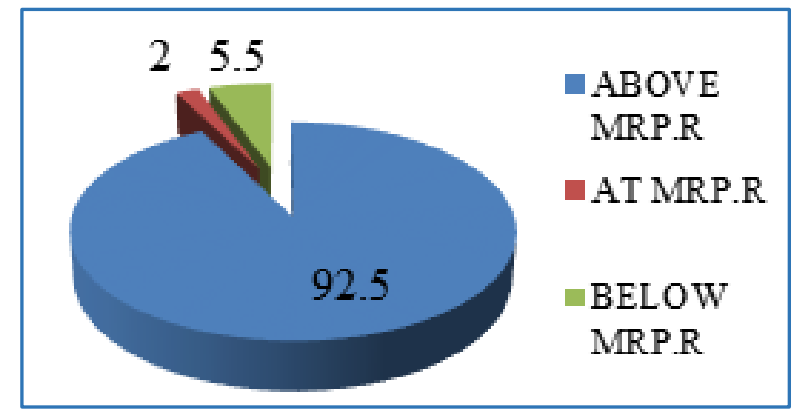

Fig. 2c- Position of Axis in Relation to MRP-HR (Female)-R

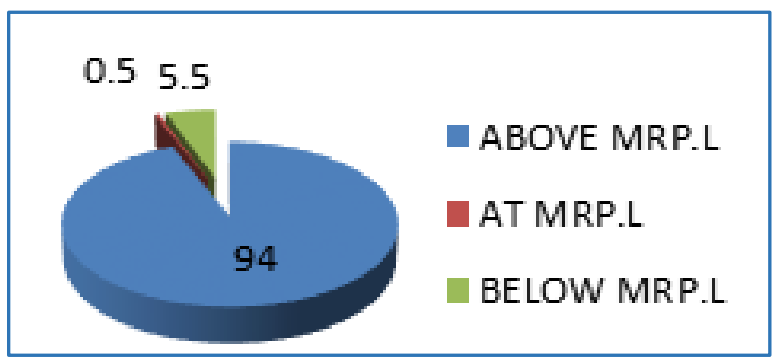

Fig. 2d-Position of Axis in Relation to MRP-HR (Female)-L

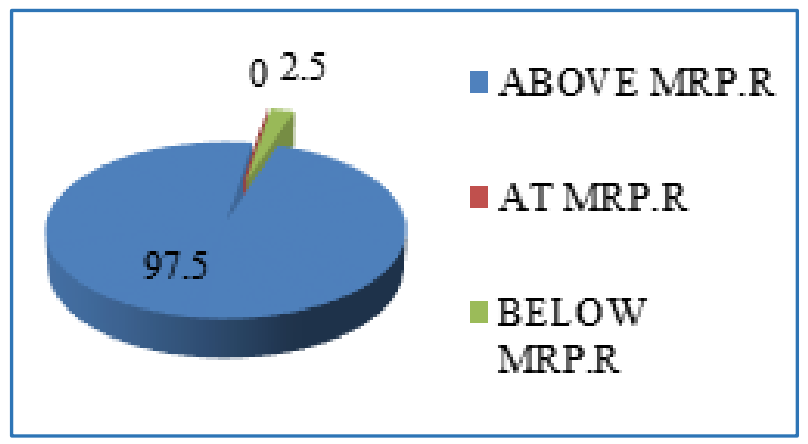

Fig. 3a-Position of Axis in Relation to MRP-HP (Male)-R

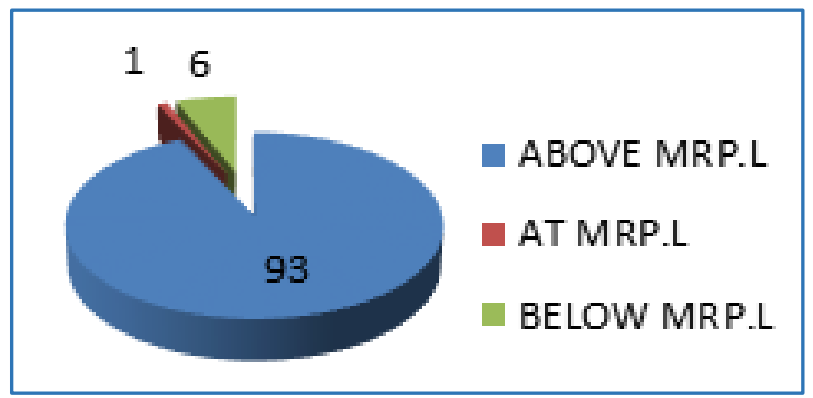

Fig. 3b-Position of Axis in Relation to MRP-HP (Male)-L 


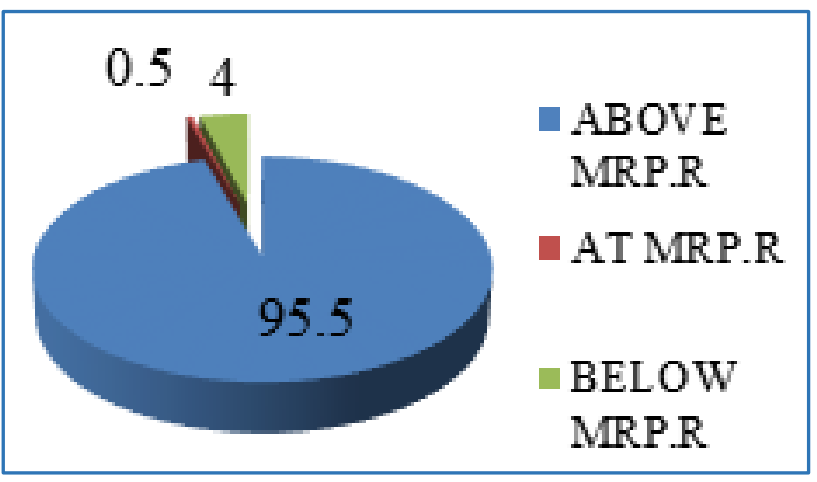

Fig. 3c-Position of Axis in Relation to MRP-HP (Female)-R

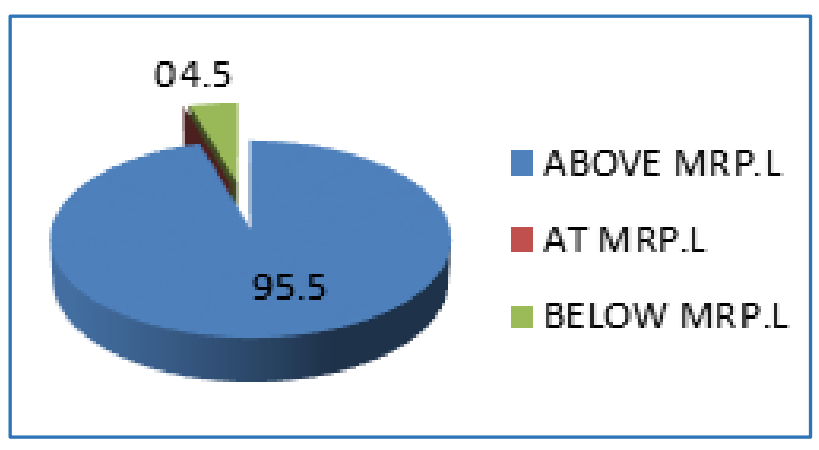

Fig. 3d-Position of Axis in Relation to MRP-HP (Female)-L

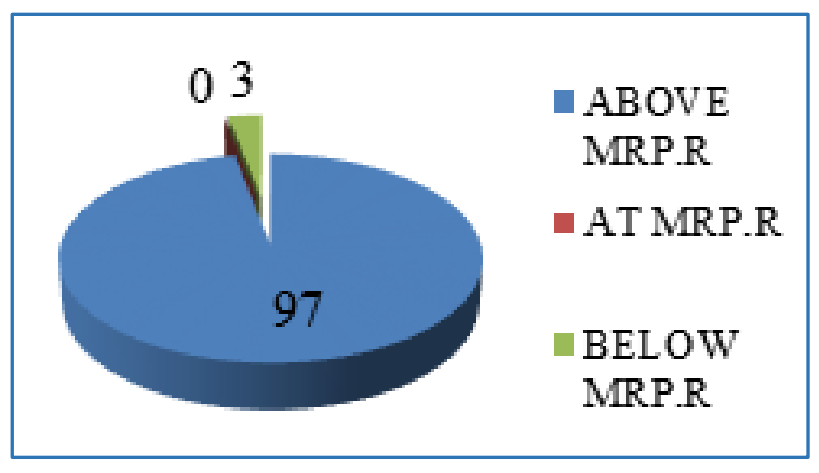

Fig. 4a-Position of Axis in Relation to MRP-OD (Male)-R

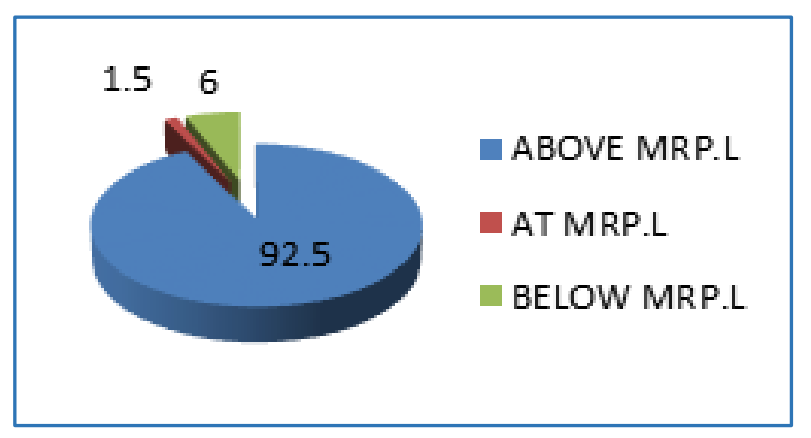

Fig. $4 b$ - Position of Axis in Relation to MRP-OD (Male)-L

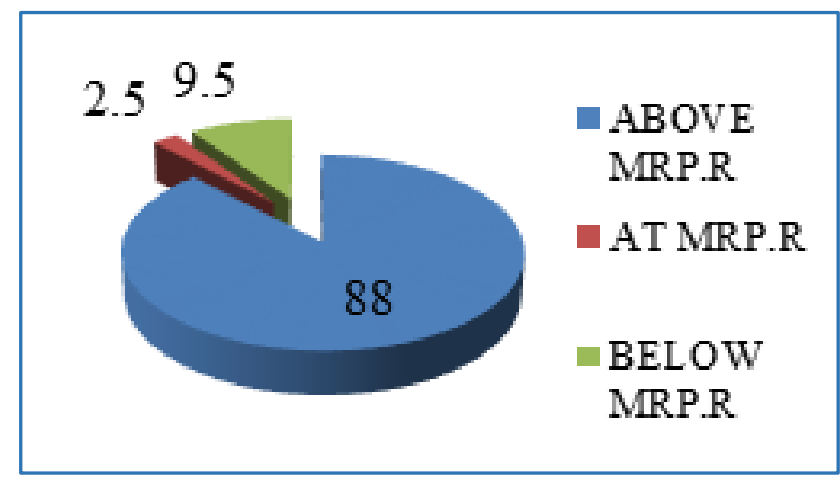

Fig. 4c-Position of Axis in Relation to MRP-OD (Female)-R

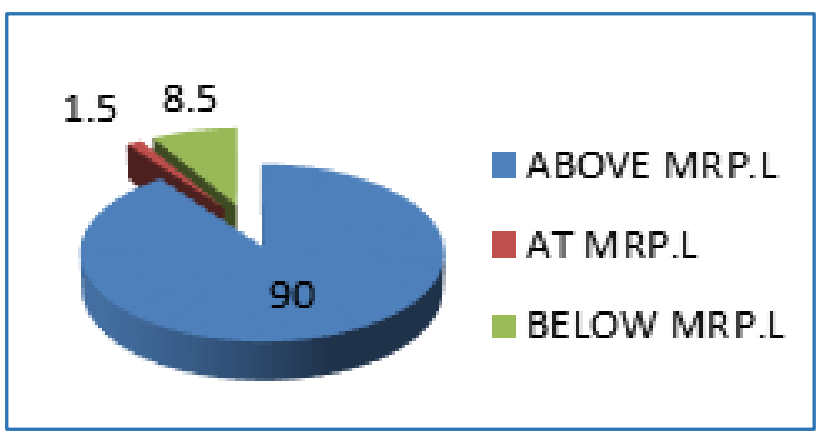

Fig. 4d-Position of Axis in Relation to MRP-OD (Female)-L

\section{DISCUSSION}

The position of transverse axis of temporomandibular joint was determined by using three parameters, i.e. CAGAI, MRDAP and in relation to MRP which were derived after superimposition of two triangles and intersection of their CYGo arms in the present study. The mean CAGAI is 50 in general and on both sides, which suggests that the upper (CA) segment above the axis point is one-fourth of the length of the ramus (Cy-Go) and the lower (GA) segment being threefourth of the ramus (Cy-Go) of mandible; the transverse axis of temporomandibular joint is generally situated at the junction between upper one-fourth and lower three-fourth on ramus on both sides. Sexual variation in the position of this transverse axis has been marked as the mean CAGAI is 46.28 in males and in females 54.03. In males, according to the CAGAI, the axis is situated little above the junction between upper one-fourth and lower three-fourth of the ramus, while in females little below this junction.

The position of transverse axis is also considered from the midramus deviation of the axis point (MRDAP) and reveals that in general this axis is situated $11 \mathrm{~mm}$ above the Midramus Point (MRDAP) on both sides.

In Haryanvi, in males, axis is situated above MRP in $96.75 \%$ and in females in $93.25 \%$ cases; in both Himachali males and females above MRP in 95.5\%, while in Odisha males above MRP in $94.75 \%$ and in females in $89 \%$ cases. The Himachali females maintain the bilateral symmetry in the position of axis and also Odisha females to same extent.

\section{CONCLUSION}

In this study, the transverse axis of temporomandibular joint is generally situated at the junction between upper onefourth and lower three-fourth on ramus on both sides. Sexual 
variation in the position of this transverse axis has been marked as the mean CAGAI is 46.28 in males and in females 54.03. In males according to the CAGAI, the axis is situated little above the junction between upper one-fourth and lower three-fourth of the ramus, while in females little below this junction.

From the Midramus Deviation of the Axis Point (MRDAP), it reveals that in general this axis is situated $11 \mathrm{~mm}$ above the Midramus Point (MRP) on both sides.

The Himachali females maintain the bilateral symmetry in the position of axis and also Odisha females to same extent.

Haryanvi males on the right side present their axis above MRP in highest number of cases (98.5\%), while Himachali females on both sides in highest number of cases (95.5\%). But Odisha females comparatively present the axis above MRP in less number of cases, i.e. $88 \%$ on the right side and $90 \%$ cases on the left side.

Similar study was also conducted by L. Pattnaik and P. C. Maharana by adapting the same new superimposition method and their findings about the position of the transverse axis of temporomandibular joint are more or less similar to that of the present study. According to their study, the position of the axis varies from individual to individual and also with age, sex and other factors. The axis is present above MRP in $100 \%$ of males on the right side and $96.66 \%$ on the left side, while $96.66 \%$ females on the right side and $76.66 \%$ on the left side. ${ }^{3}$ However, the findings of the present study is not supported by the reports of the earlier Authors. $4,5,6$

\section{ACKNOWLEDGEMENT}

I pay my sincere thanks to Dr. Y. Roja Ramani (Assistant Professor), Dr. Abinash Panda (Assistant Professor), Department of Pharmacology. MKCG Medical College, Berhampur, Odisha for their valuable help in statistically analysing the data in the present study. I dedicate this work to my family members, who stood as pillar and motivate to continue my present research.

\section{REFERENCES}

[1] Okeson JP. Functional anatomy and biomechanics of the masticatory system. In: Management of temporomandibular disorders and occlusion. $6^{\text {th }}$ edn. Mosby Elsevier 2008:p. 7.

[2] Lindauer SJ, Sabol G, Isaacaso RJ, et al. Condylar movement and mandibular rotation during jaw opening. Am J Orthod Dentofacial Orthop 1995;107(6):573-7.

[3] Pattnaik L, Maharana PC. Determination of the transverse axis of temporomandibular joint by using a new method. Anatomical science International, Blackwell publishing. $16^{\text {th }}$ International congress of the IFAA proceedings 2004;79:3-051.

[4] Last RJ. Anatomy regional and applied. $6^{\text {th }}$ edn. Edinburgh: Churchill Livingstone 1978.

[5] Sharma RN. Disorders of the temporomandibular joint. In: Sinha RN, ed. A textbook of plastic surgery in the topics. Orient Longman 1976.

[6] Standring S. Gray's anatomy. 38 th edn. London: Churchill Livingstone 1999. 